\title{
O USO DE GEOPOLÍMEROS COMO ALTERNATIVA SUSTENTÁVEL NA CONSTRUÇÃO CIVIL
}

\author{
Arissa Silva Nogueira \\ Engenheira Civil pelo CEFET/RJ, Rio de Janeiro, RJ, Brasil. \\ arissa.nogueira@gmail.com \\ Lais Amaral Alves \\ Professora de Engenharia Mecânica pelo CEFET/RJ \\ Mestre em Engenharia Civil pela COPPE UFRJ, Rio de Janeiro, RJ, Brasil. \\ lais.alves@cefet-rj.br
}

\section{RESUMO}

Patenteados no início dos anos 80 , os geopolímeros trouxeram novas oportunidades de obtenção de cimentos especiais e, usados como aglomerantes, podem ser utilizados com substituição parcial ou total do tradicional Portland. Porém, com a preocupação crescente a respeito da preservação ambiental, é pela baixa emissão de $\mathrm{CO}_{2}$ e o baixo consumo de energia que os cimentos geopoliméricos chamam cada vez mais atenção. Neste artigo, serão apresentados como a descoberta e o uso dos geopolímeros podem ser úteis na busca de um desenvolvimento sustentável na construção civil, ou seja, um desenvolvimento no qual haja crescimento econômico e social, mas também se conserve o meio ambiente. Serão citados de forma breve o que são, como são obtidos, o principal uso e vantagens dos geopolímeros.

Palavras-chave: Geopolímero. Construção Civil. Construção Sustentável.

\section{THE USE OF GEOPOLYMERS AS A SUSTAINABLE ALTERNATIVE IN CIVIL CONSTRUCTIONS}

\begin{abstract}
Patented in the early 1980's, geopolymers have brought new opportunities for special cements and, used as binders agents, can be used in parcial or total replacement to traditional Portland. However, with growing concern about environmental preservation, it is because of the low $\mathrm{CO}_{2}$ emissions and the low energy consumption that geopolymeric cements call increasing attention. In this article, it will be presented how the discovery and use of geopolymers can be useful in the search for a sustainable development in the construction industry, that is, a development in which there is economic and social growth, but also the environment. They will briefly be quoted what are, as they are obtained, the main use and advantages of geopolymers.
\end{abstract}


Keywords: Geopolymer. Construction. Sustainable construction. 


\section{INTRODUÇÃO}

Nas últimas décadas, houve uma crescente preocupação com o meio ambiente e sua degradação, sendo tema de várias convenções mundiais que buscavam soluções que melhorassem a relação entre o homem, suas atividades, e o ambiente em que vivem. Entre essas soluções pode-se destacar como formas de preservação do meio ambiente a economia de água, a produção de energia limpa, a preservação da fauna e flora, o gerenciamento responsável dos resíduos e a preservação dos recursos naturais.

Paralelamente a isso, no final dos anos 70 e início dos anos 80 , as pesquisas de novos compostos químicos que pudessem otimizar os processos da engenharia avançaram, e a partir da síntese de alguns minerais em meio alcalino, surgiram os geopolímeros, compostos ricos em alumínio e sílica que apresenta excelentes propriedades em termos de resistência mecânica e durabilidade, podendo ser usados para substituir o cimento Portland, porém oriundos de fontes naturais e com características menos agressivas ao meio ambiente.

Este trabalho apresenta algumas características fundamentais dos geopolímeros e algumas vantagens que o tornam uma ótima opção a ser usada na construção, seja do ponto de vista técnico, ou da preservação ambiental.

\section{POLÍMEROS}

Polímeros são denominações dadas às grandes moléculas orgânicas, ou macromoléculas, formadas a partir da repetição de unidades menores, os monômeros. Já os chamados Geopolímeros ou polissialatos (abreviatura de poli-silico-aluminatos) são materiais obtidos da poli-condensação de aluminossilicatos sólidos, ativada por uma solução alcalina aquosa concentrada de hidróxido ou silicato. 


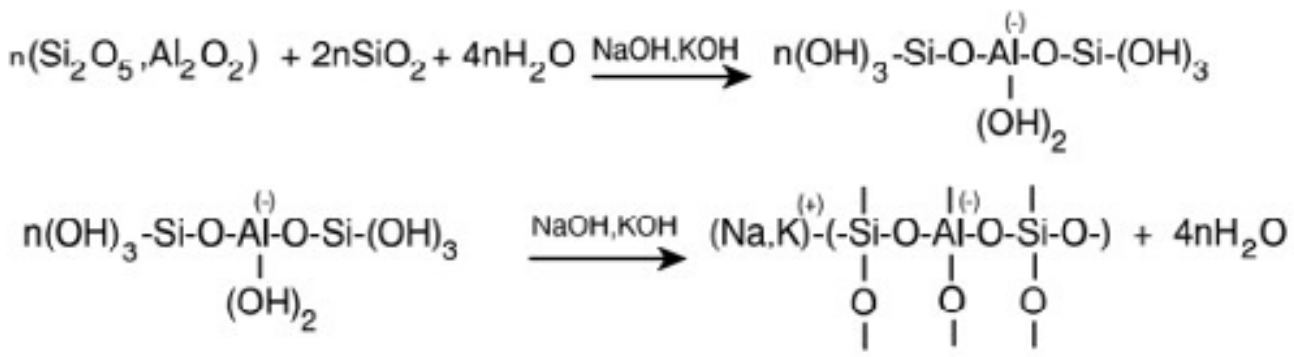

Fonte: http://popeng.com.br/geopolimeros/

Esses compostos começaram a surgir no final dos anos 70, mas só no início dos anos 80, em 1981, foram patenteados pelo Prof. J. Davidovits, onde foram apresentados vários exemplos de mistura de reagentes e processos de obtenção. Joseph Davidovits, hoje presidente do Geopolymer Institute, começou sua pesquisa procurando por compostos resistentes à altas temperaturas. Foi quando descobriu através de estudos mineralógicos e químicos que os blocos das grandes pirâmides do Egito erguidas, há 4.500 anos, não são de pedra calcária natural, e sim de um concreto feito a partir da mistura de pedregulhos de calcário caulinítico oriundos de Gizé com $\mathrm{NaOH}$, produzido no local pela mistura de cal $\left(\mathrm{Ca}[\mathrm{OH}]_{2}\right)$, barrilha $\left(\mathrm{Na}_{2} \mathrm{CO}_{3}\right)$ e água, fato publicado em uma publicação intitulada 'The Pyramids: An Enigma Solved". Estes compostos também são comumente encontrados em amostras de estruturas antigas existentes na Grécia, Chipre e Itália. (da Silva et. al, 2006) A partir dessa descoberta, Davidovits desenvolveu os compostos geopoliméricos que foram capazes de se transformar em cimentos. Em 1983 as indústrias Lone Star começaram a usar um tipo inicial de cimento geopolimérico, o Pyrament, usado para a pavimentação. (Geopolymer System, acesso 2017)

Um outro estudioso que pesquisou sobre a durabilidade dos cimentos antigos, foi Viktor Glukhovsky, do Instituto de Engenharia Civil de Kiev, na Ucrânia. Suas pesquisas começaram ainda nos anos 50 e mostraram que as características dos cimentos usados na Antiguidade variam conforme sua composição química e que eles, em sua maioria, apresentavam ligantes de base alcalina a partir de aluminossilicatos do tipo da escória industrial e suas constituições variavam conforme a matéria prima obtida no local. (Geopolymer System, acesso 2017) 
Com o crescimento do ramo da construção civil, houve também o crescimento do consumo de um importante elemento usado nessas construções: o cimento. Usado como aglomerante no concreto, o cimento teve um alto crescimento de consumo no mundo e especialmente, nos países em desenvolvimento. Se por um lado o aquecimento da construção civil significou aumento de desenvolvimento econômico e social, por outro lado, também causou preocupações aos ambientalistas, uma vez que o cimento é também um grande emissor de $\mathrm{CO}_{2}$, além de ser um grande consumidor de recursos naturais na produção desse material. A liberação do gás ocorre na etapa de combustão e descarbonatação do processo de produção do cimento. Portanto, é de fundamental importância o desenvolvimento de outros materiais que possam servir como alternativa ao cimento, porém que seja menos nocivo ao meio ambiente. (Vignatti, 2012)

Nessa corrida por novos produtos, o cimento geopolimérico desponta como um principal candidato a substituir o tradicional e altamente poluente cimento Portland, por apresentar alta resistência, mas com baixo consumo de energia e baixa emissão de $\mathrm{CO}_{2}$. Um importante fator para o desenvolvimento do geopolímero foi o início do uso de uma substância pozolânica chamada de Metacaulim.

Ainda fruto de pesquisas em vários países, o Metacaulim é constituído basicamente de sílica ( $\mathrm{SiO}$ ) e alumina (Al2O3) na fase amorfa, capaz de reagir com o hidróxido de cálcio $\mathrm{Ca}(\mathrm{OH})$. Esta pozolana acelera o processo de hidratação do cimento, formando silicato de cálcio hidratado (C-S-H) adicional. (Medina, 2011)

O produto chamado atualmente de cimento geopolimérico é o nome dado ao geopolímero do tipo polisiloxossialato de sódio, potássio e cálcio (Na,K,Ca-PSS) capaz de desenvolver propriedades tixotrópicas, elevada resistência mecânica, dureza superficial e durabilidade. Ele pode ainda ser combinado com aditivos especiais e ganhar outras propriedades tais quais resistência química, ultra-alta resistência inicial e refratariedade.

O cimento geopolimérico é bastante versátil em seus usos, que variam conforme ao caráter polimérico do material, ou seja, à relação Si/Al e ao tamanho da cadeia polimérica. Na figura abaixo pode-se observar a variação dos usos conforme a composição polimérica.

A qualidade do produto final depende principalmente da origem do substrato utilizado (escória de alto forno, metacaulim, pozolana, cinza volante, etc.). Mas, algumas características principais são comuns aos cimentos geopolimérico, como: pega rápida, pasta de cimento fresca com reologia semelhante à das resinas orgânicas, alta resistência 
inicial (sendo uma ótima solução para obras que necessitam de liberação rápida de tráfego, como estradas e também pavimentação de aeroportos), altas resistências à compressão e à flexão, forte aderência à armadura, durabilidade ao tráfego, resistente ao calor e ao ataque de sulfatos, dá origem a um concreto autoadensável, resistência à abrasão, . Segundo o Geopolymer Institute, para uma mesma relação de água e aglomerante seco, o concreto de cimento geopolimérico apresenta "slump" superior ao do concreto de cimento Portland. (Geopolymer System, acesso 2017) 
Figura 2- Relação entre composição e usos

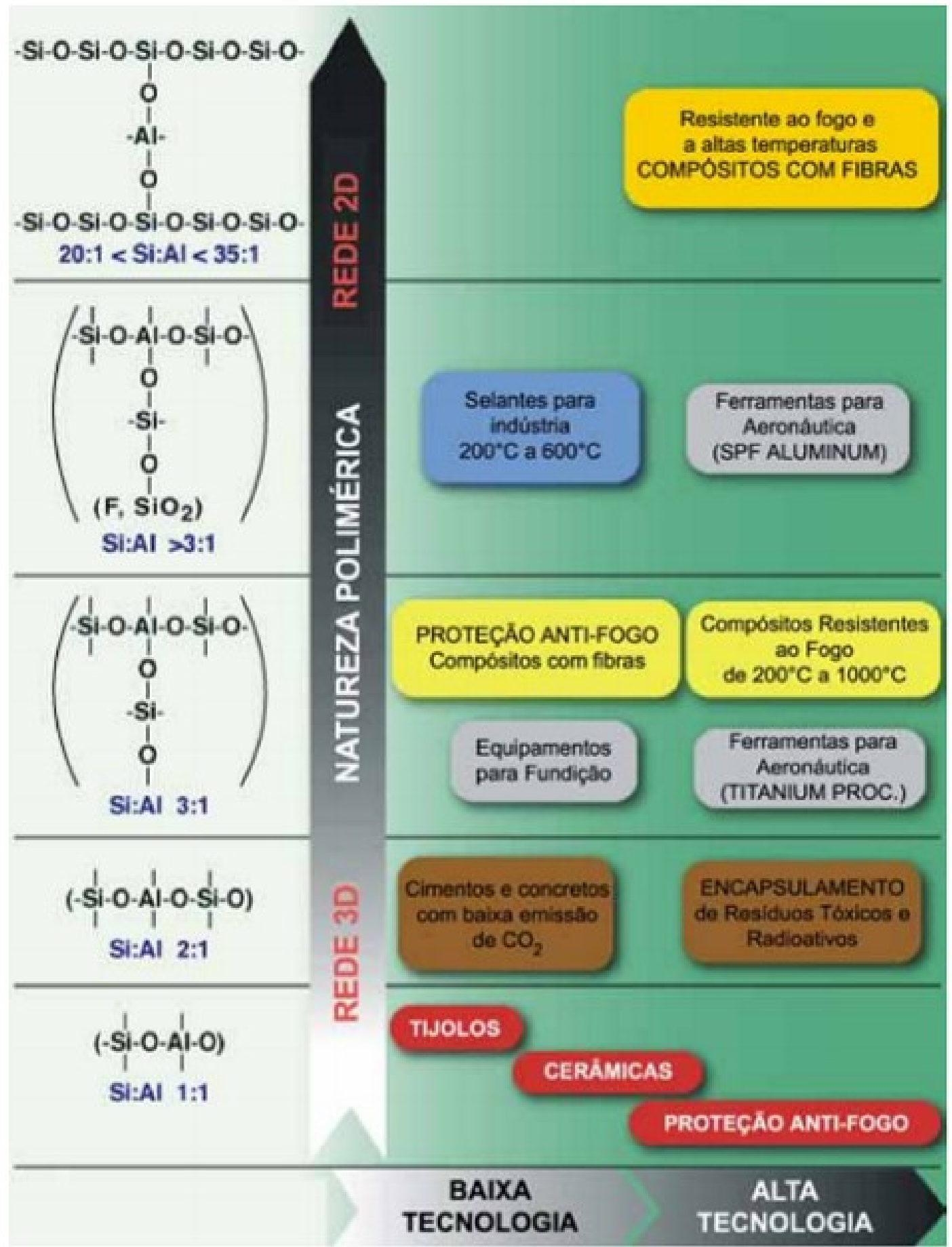

Fonte: http://www.geopolymer.com.br/PDF/introducao.pdf 
Quanto à resistência à compressão, uma comparação pode ser encontrada na tabela a seguir (Tabela 1), que compara a composição dos concreto tipo GA, M9, PPC C20/25 e CV60, demonstrando a quantidade em $\mathrm{kg} / \mathrm{m}^{3}$ de cada material e sua resistência à compressão após 28 dias.

Tabela 1 - Resistência à compressão de diferentes composições de concreto

\begin{tabular}{|c|c|c|c|c|c|c|c|c|}
\hline \multirow[b]{2}{*}{$\begin{array}{l}\text { Tipo de } \\
\text { concreto }\end{array}$} & \multicolumn{7}{|c|}{ Composiç̧ăo (kg/m3) } & \multirow[b]{2}{*}{ 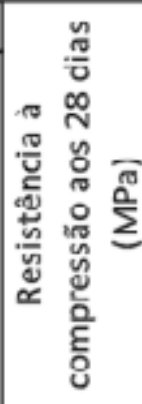 } \\
\hline & 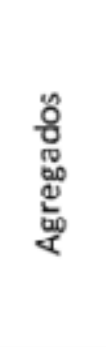 & $\frac{\pi}{4}$ & 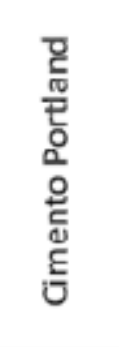 & 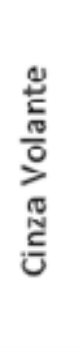 & 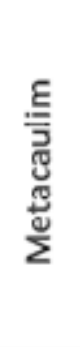 & 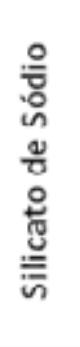 & 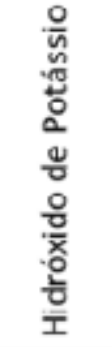 & \\
\hline GA & 930 & 792 & - & - & 300 & 200 & $\begin{array}{c}100 \\
(15 \mathrm{M})\end{array}$ & 57 \\
\hline M9 & 1756 & - & - & 476 & - & 120 & $\begin{array}{c}48 \\
(8 \mathrm{M})\end{array}$ & 60 \\
\hline $\begin{array}{c}P P C \\
C 20 / 25\end{array}$ & 880 & 812 & $\begin{array}{c}370 \\
\text { Tipo II }\end{array}$ & - & - & - & - & 25 \\
\hline CV 60 & 850 & 774 & $\begin{array}{c}200 \\
\text { Tipo I }\end{array}$ & 300 & - & - & - & 35 \\
\hline
\end{tabular}

Fonte: http://www.geopolymer.com.br/PDF/cpxgp.pdf

Além dessas características, o cimento geopolimérico apresenta como principal vantagem, e ponto de partida desse trabalho, o baixo impacto ambiental, contribuindo para o desenvolvimento ecológico. Um dos pontos que torna esse material bom para o meio ambiente é a baixa necessidade de energia para sua produção. Apenas é necessária energia para obter temperaturas de cerca de 600 C para a obtenção de de alguns dos substratos que podem ser utilizados, como as pozolanas. Quanto às emissões de $\mathrm{CO}_{2}$ para a atmosfera, elas são igualmente insignificantes, chegando a ser até 6 vezes menor se comparado com a produção de cimento Portland. Essa redução se dá ao uso, principalmente, de argilominerais naturais e sintéticos diferentemente da indústria cimentícia tradicional, que tem como principal fonte matéria calcária para gerar o clínquer do cimento Portland. Ainda em relação à matéria prima, outra vantagem sustentável é que é possível criar um geopolímero através do uso de produtos cuja 
composição contenha quantidades de silica e alumina, bem como é possível também utilizar subprodutos disponíveis na indústria como escórias de alto forno e cinza volante.

Ainda pode-se destacar como vantagens do cimento polimérico: processo de produção simples, bastando realizar a mistura da pozolana com o fluido alcalino, boa estabilidade volumétrica do geopolímero, com um coeficiente de retração 4/5 inferior ao do cimento Portland, Ganhos rápidos de resistência: estudos indicam que os geopolímeros adquirem cerca de $70 \%$ da resistência à compressão em 4 horas, elevada resistência ao fogo, conseguindo resistir a temperaturas de 1000 o C a 1200 C sem perder características funcionais e baixa condutividade térmica, variando entre de 0,24 a 0,3 w/m.k. (Sepúlveda, 2007)

A vantagem do uso do cimento geopolimérico fica ainda mais evidente se fizermos uma comparação com o tradicional e mais utilizado cimento Portland. Nos gráficos abaixo encontram-se comparações de perda de resistência devido à altas temperaturas (Figura 3), perda de peso após ataques de ácidos (Figura 4) e reação álcali-sílica (Figura 5).

Figura 3 - Comparação de resistência à compressão devido ao aumento da temperatura

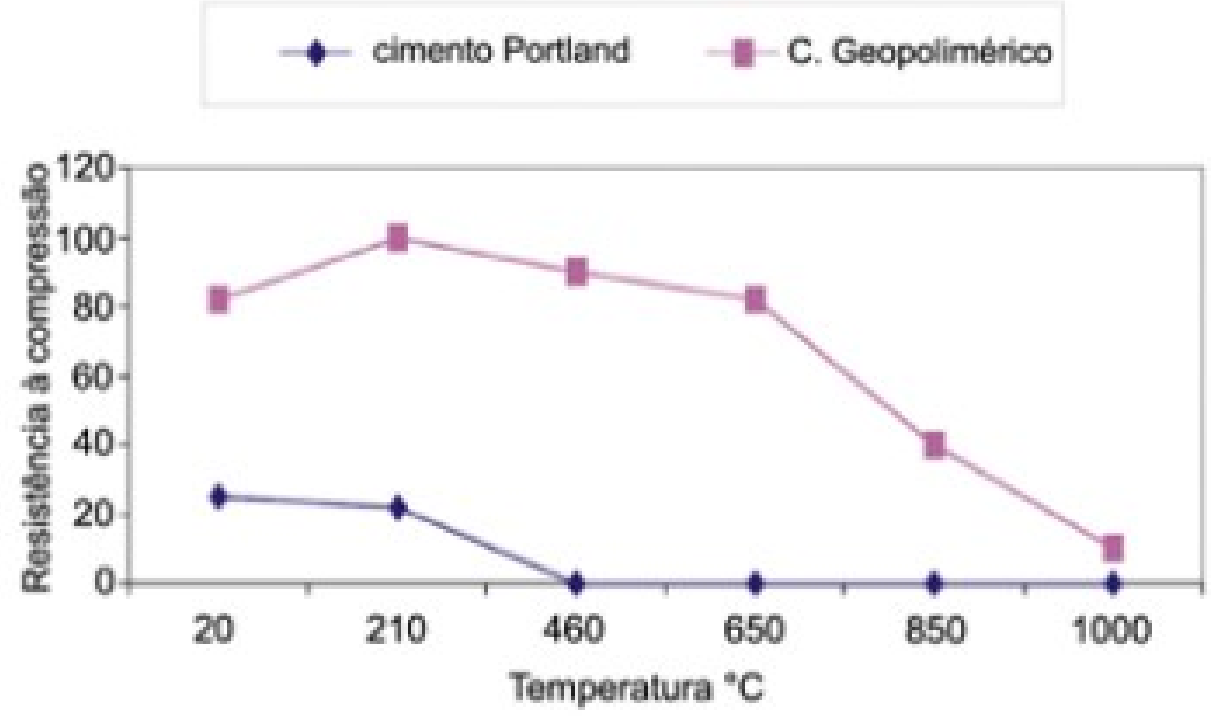

Fonte: http://www.geopolymer.com.br/PDF/cpxgp.pdf 
Figura 4 - Perda de peso devido à ataques de ácidos

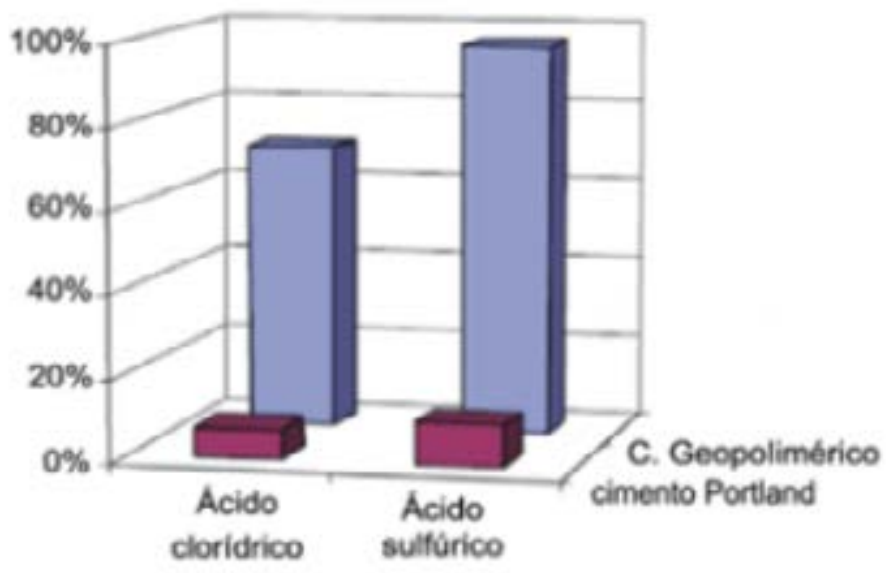

Fonte: http://www.geopolymer.com.br/PDF/cpxgp.pdf

Figura 5 - Reação álcali-sílica. Medição da expansão das argamassas

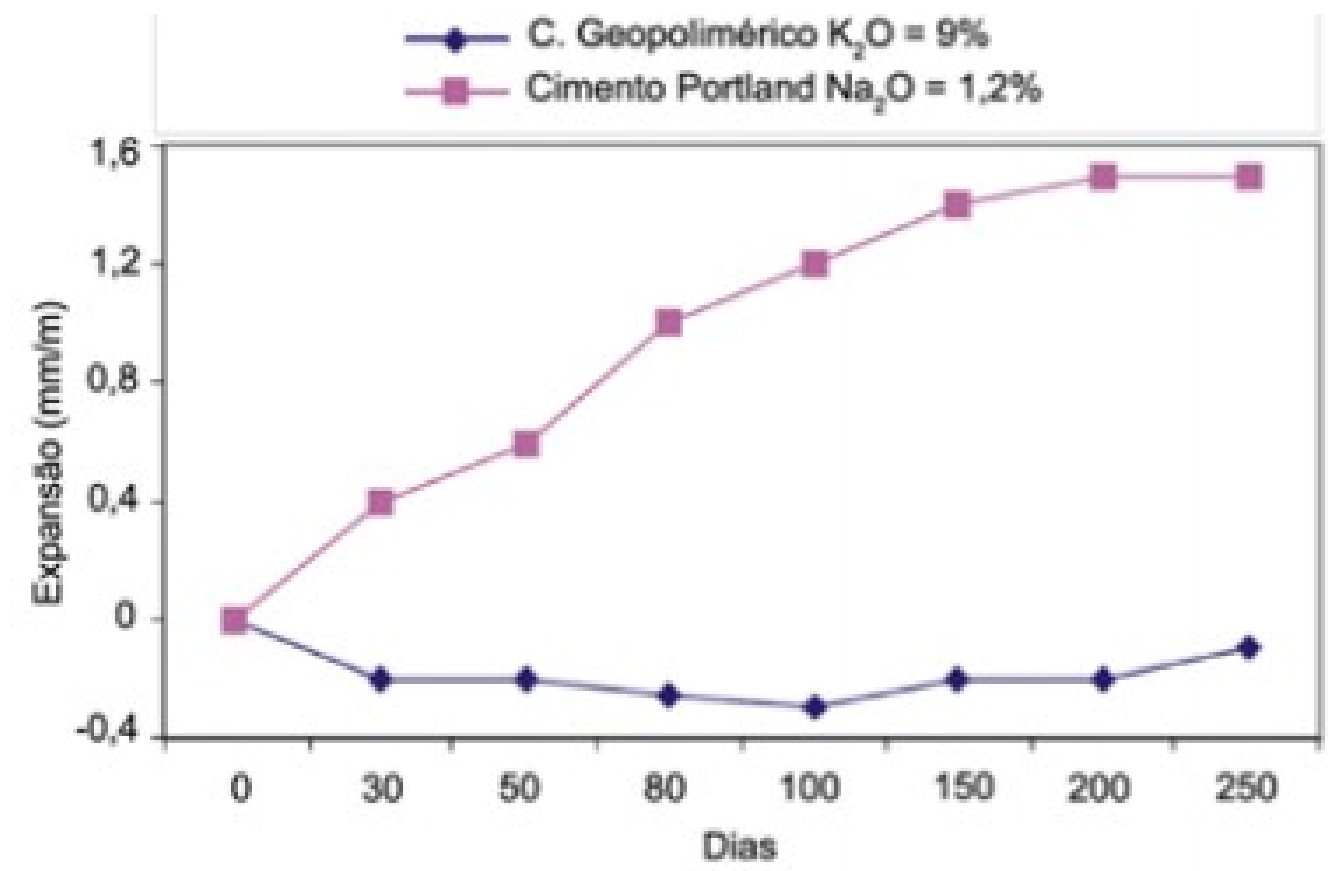

Fonte: http://www.geopolymer.com.br/PDF/cpxgp.pdf 


\section{CONSIDERAÇÕES FINAIS}

Os geopolímeros vêm sendo alvo de estudo há muitos anos, não por um acaso: eles têm um amplo campo de aplicação devido às suas características especiais: indo desde reforço estrutural, geotecnia, reabilitação e utilização em estruturas que estejam sujeitas a ataques de ácidos e se apresenta mais vantajoso em diversos aspectos técnicos se comparado ao cimento mais utilizado, o Portland.

No entanto, essas não são as principais vantagens do cimento geopolímerico, uma vez que algumas dessas características podem ser obtidas também com o uso de aditivos acrescidos à mistura do cimento Portland. A principal vantagem obtida com o uso dos geopolímeros e que não pode ser equiparada com outros é o baixo impacto ambiental, com uma produção mais limpa, com mais fácil acesso à matéria prima, baixo consumo de energia e baixa emissão de dióxido de carbono para a atmosfera, ele desponta como uma grande solução para diminuir um problema tão atual e importante: os impactos ambientais gerados pela construção civil.

A baixa resistência à tração e à flexão normalmente exibida pelos geopolímeros devido à sua natureza quebradiça e cerâmica pode facilmente levar a falhas e representar a principal desvantagem que limita o uso desses materiais em várias aplicações. Para melhorar a resistência à flexão e a resistência à fratura, os compostos de geopolímeros reforçados com fibra podem ser considerados como uma solução. 


\section{REFERÊNCIAS}

DA SILVA, F.J.; DE OLIVEIRA, M. C.; MACHADO, M.V.S.; DUARTE, F. P. e Thaumaturgo, C. Cimentos Geopoliméricos. IME. Rio de Janeiro, 2006. Disponível em: <http://www. materia.coppe.ufrj.br/sarra/artigos/artigo10055/>. Acesso em: 07 de abril de 2017.

ENGENHARIA POPULAR. Geopolímeros. 2013. Disponível em: <http://popeng.com.br/ geopolimeros/>. Acesso em: 11 de março de 2017.

GEOPOLYMER SYSTEM. Cimento Portland versus Ligantes Geopoliméricos. s.d. Disponivel em: <http://www.geopolymer.com.br/PDF/cpxgp.pdf>. Acesso em: 25 de março de 2017.

GEOPOLYMER SYSTEM. Geopolímero para principiantes. s.d. Disponível em: $<\mathrm{http}: / /$ www.geopolymer.com.br/PDF/apresentacao.pdf>. Acesso em: 25 de março de 2017.

GEOPOLYMER SYSTEM. Introdução ao Estudo dos Geopolímeros. s.d. Disponível em: $<$ http://www.geopolymer.com.br/PDF/introducao.pdf >. Acesso em: 25 de março de 2017.

MEDINA, A. E. Pozolanicidade do metacaulim em sistemas binários com cimento Portland e hidróxido de cálcio. USP. São Paulo, 2011. Disponível em: <http://www. teses.usp.br/teses/disponiveis/3/3146/tde-12032012-120653/pt-br.php>. Acesso em: 07 de abril de 2017.

SEPÚLVEDA, Jacinto. Geopolímeros. Tudo sobre Engenharia Civil, 2007. Disponível em: < https://engenhariacivil.wordpress.com/2007/07/03/geopolimeros/>. Acesso em: 11 de março de 2017.

VIGNATTI, Regina. Geopolímeros Aplicados à Engenharia Civil. Porto Alegre, 2012. Disponível em:

< http://www.lume.ufrgs.br/handle/10183/106247>. Acesso em: 11 de março de 2017. 